\title{
Inovasi Pengabdian Pusat Kesehatan Matematika Sekolah (Puskesmas) dalam Pembelajaran Matematika Berbasis Alun-alun Kota
}

\author{
Supriadi ${ }^{1}$ \\ 1 Universitas Pendidikan Indonesia, Indonesia
}

\begin{abstract}
A B S T R A C T
COMMUNITY SERVICE INNOVATION OF THE SCHOOL MATHEMATICS HEALTH CENTER (PUSKESMAS) IN LEARNING MATHEMATICS BASED ON THE TOWN SQUARE. The purpose of this study was to develop an innovation in the school's mathematics health center in mathematics learning through city square-based mathematics learning. Descriptive method is used with subjects in early childhood and elementary school students who are in the location of the school mathematics health center. The instrument used by the researcher itself, data collection techniques using structured interviews, observation and documentation. The data analysis technique used triangulation, data reduction, data presentation and conclusion drawing. The results showed that the media presented at the Puskesmas were all new and they had not yet gotten them in their respective schools. The attitude of students who become happy, like, cheerful in learning mathematics and easy to understand mathematical concepts, and bring out the creativity of early age and elementary school students in learning mathematics. Student concentration also increases because the learning model used uses an individual approach, so that they can focus more on seeing the student learning process. Parents who accompany their children generally feel happy because their children enjoy learning mathematics. Puskesmas activities have an impact on early age and elementary school students to be happy learning mathematics, like learning with mathematics media, cheerful in following math tutoring and enjoy learning mathematics. This program is also highly supported by parents because it is very helpful in the learning process of their children and eases the family's economic burden in education.
\end{abstract}

Keywords: Mathematics Lessons, Town Square.

\begin{tabular}{llll}
\hline Received: & Revised: & Accepted: & Available online: \\
18.01 .2020 & 25.08 .2020 & 29.10 .2020 & 30.11 .2020 \\
\hline
\end{tabular}

\section{Suggested citation:}

Supriadi. (2020). Inovasi pengabdian pusat kesehatan matematika sekolah (Puskesmas) dalam pembelajaran matematika berbasis alun-alun kota. Jurnal Pengabdian Pada Masyarakat, 5(4), 10871096. https://doi.org/10.30653/002.202054.403

Open Access I URL: http://ppm.ejournal.id/index.php/pengabdian/article/view/403

${ }^{1}$ Corresponding Author: Universitas Pendidikan Indonesia (UPI) Kampus Serang. Jl. Ciracas No.38, Serang, Kec. Serang, Kota Serang, Banten 42116, Indonesia. Email: supriadi.upiserang@upi.edu 


\section{PENDAHULUAN}

Inovasi pembelajaran matematika harus terus dilakukan agar menghasilkan kualitas hasil belajar siswa yang tinggi.Guru memerlukan pengetahuan yang baru sehingga siswa yang diajarnya mendapat informasi kebaruan dalam pembelajaran matematika. Hal ini sejalan dengan Supriadi (2016) bahwa guru dan siswa harus kreatif, inovatif, tekun dalam pembelajaran matematika.

Faktor-faktor yang mendukung peningkatan hasil belajar siswa diantaranya adalah bimbingan belajar yang langsung berinteraksi dengan siswa sehingga pengajar mengetahui kesulitan siswa dalam belajar matematika. Permasalahan siswa dalam belajar matematika yang diperoleh penulis adalah kurang optimalnya pemahamaan siswa saat memperoleh pembelajaran di sekolahnya karena mereka masih berpendapat matematika pelajaran yang sulit dan tidak menarik. Hal ini didukung oleh pendapat Widjajanti (2009) bahwa siswa menganggap matematika sebagai pelajaran yang sulit dan sangat abstrak, akibatknya siswa tidak cukup percaya diri dan berdampak pada kurang optimalnya prestasi yang diperoleh.

Satu orang guru dengan siswa yang banyak, tidak menutup kemungkinan pesan dari guru belum tersampaikan secara penuh kepada otak siswa, sehingga siswa dalam belajar matematika mengalami kesulitan. Pendapat penulis ini sesuai dengan penelitian Hasan (2015) bahwa kendala pembelajaran matematika bukan disebabkan guru, namun disebabkan besarnya jumlah siswa dalam satu kelas yang akhirnya akan menyulitkan guru dalam melaksanakan tugasnya dengan baik.

Siswa SD dalam belajar matematika masih didominasi oleh perasaan tidak suka, tidak senang, sehingga berdampak pada psikologi dalam semangat belajar siswa. Pernyataan ini sesuai dengan penelitian Supriadi (2008) bahwa matematika dianggap oleh siswa kurang menarik, menakutkan.Perasaan yang demikian muncul karena dipengaruhi oleh faktor-faktor seperti mengajar matematika yang kurang ceria, penuh ketegangan,sehingga siswa pun menjadi kaku untuk berpikir dan berekspresi dalam pembelajaran matematika.Saat ini program Bimbingan Belajar telah menjamur di kotakota besar, namun terdapat kendala bagi siswa-siswa yang kurang mampu membayar biaya belajarnya, akhirnya mereka tidak bisa mengikuti program tersebut, seperti teman-temannya.Susanti dan Maharani (2015) menyatakan bahwa saat ini tumbuh fenomena menjamurnya lembaga bimbingan belajar di Indonesia.Soekirno (2017) biaya bimbel yang mahal mencapai jutaan rupiah membuat siswa menolak masuk bimbel.

Sehingga untuk mengatasi permasalahan kurang optimalnya penyampaian materi ke siswa, pembelajaran matematika yang tegang, ingin ikut Bimbel tapi kurang mampu membayar maka penulis mendirikan Puskesmas (Pusat Kesehatan Matematika Sekolah) sebuah bimbingan belajar matematika gratis bagi siswa sekolah dasar dengan model bimbingan belajar berbasis alun-alun kota. Alun-alun merupakan pusat keramaian sebuah kota yang memudahkan Puskesmas dipublikasi ke masyarakat sehingga program bimbingan belajar matematika dapat langsung terasa oleh masyarakat.

Berdasarkan latar belakang tersebut peneliti mengkaji melalui penelitian desktiptif dengan judul: "Inovasi Pengabdian Pusat Kesehatan Matematika Sekolah (Puskesmas) dalam Pembelajaran Matematika Berbasis Alun-alun Kota." 


\section{METODE}

Metode yang digunakan dalam penelitian ini adalah metode deskriptif, dimana dalam metode ini hanya menggambarkan suatu fenomena atau peristiwa dengan apa adanya. Metode deskriptif dapat menggambarkan atau menjabarkan bagaimana proses bimbingan belajar Puskesmas dalam mengenalkan inovasi-inovasi pembelajaran matematika kepada siswa AUD dan SD dalam belajar matematika sedangkan data yang dikumpulkan dari kegiatan tersebut berupa kata-kata dan gambar bukan angka. Subyek penelitian yang diambil semua siswa AUD/SD dan orangtuanya yang hadir setiap minggunya di tempat belajar Puskesmas, Alun-alun Kota Serang, Banten. Instrumen yang digunakan adalah peneliti itu sendiri dan untuk teknik pengumpulan data peneliti menggunakan wawancara terstruktur, observasi dan dokumentasi. Teknik analisis data menggunakan triangulasi, reduksi data, penyajian data dan penarikan kesimpulan. Penelitian dilakukan selama 1 bulan dari pertengahan bulan April-Mei 2018.

\section{HASIL DAN PEMBAHASAN}

\section{Profil Pusat Kesehatan Matematika Sekolah (Puskesmas)}

Puskesmas merupakan sebuah komunitas sosial di bidang pendidikan matematika yang digagas oleh Dr. Supriadi,.M.Pd. Diresmikan pada 5 November 2016 bertempat di Alun-alun Timur Kota Serang yang diresmikan langsung oleh pendiri yaitu Dr. Supriadi, M.Pd yang merupakan dosen di UPI Kampus Serang, Banten dan didukung mahasiswa yang memiliki kepedulian yang sama. Didirikan atas dasar kepedulian akan tugas mencerdasakan bangsa secara sukarelawan tanpa mengharap imbalan, jadi pengurus dan volunteer yang merupakan mahasiswa UPI Kampus Serang tidak di bayar sepeserpun dalam melayani konsultasi dan bimbingan matematika. Puskesmas sendiri membuka praktek pada minggu setiap pukul 08.00-10.00 WIB bertempat di Alun-alun Timur kota Serang, disana anda akan menemukan stand Puskesmas dengan berbagai macam media pembelajaran yang akan di ajarkan kepada anak-anak usia dini dan anak sekolah dasar karena sasaran Puskesmas adalah anak-anak yang sedang bermain atau menemani orangtuanya olahraga di Alun-alun dapat mampir ke tempat bimbingan belajar.

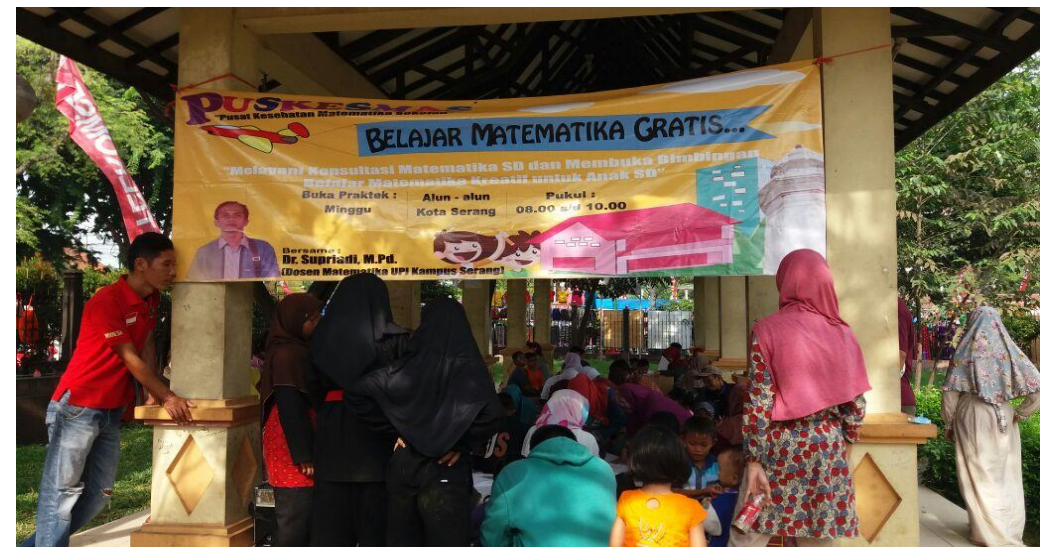

Gambar 1. Lokasi Pusat Kesehatan Matematika Sekolah di Alun-alun Kota Serang 


\section{Model Pembelajaran}

Model pembelajaran yang dilakukan di Puskesmas adalah dengan pengenalan inovasi pembelajaran berupa media pembelajaran matematika yang baru dan belum dikenal siswa AUD/SD di sekolahnya. Relawan atau pengajar Puskesmas memberikan bimbingan menggunakan pendekatan individu dengan 1-3 siswa.

\section{Inovasi Pembelajaran Matematika Minggu Pertama}

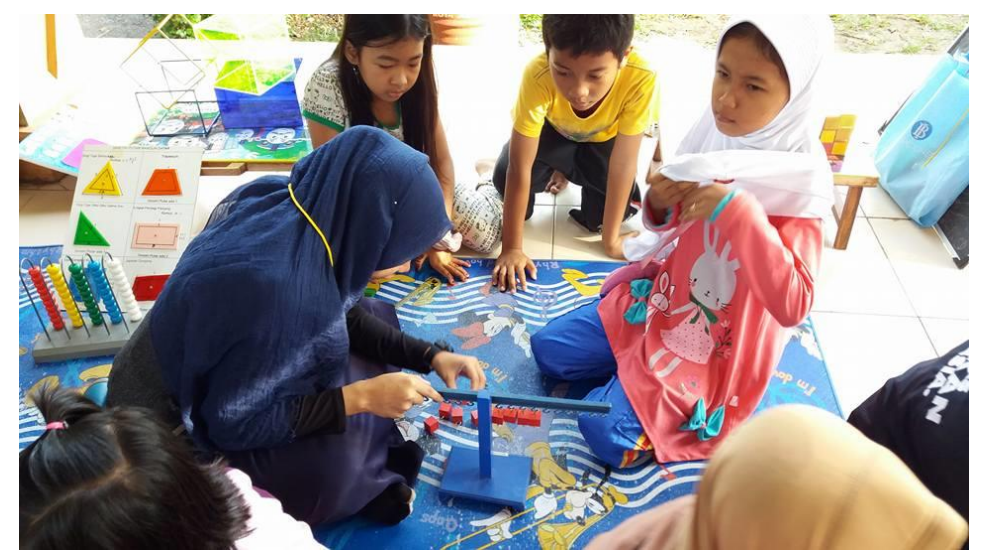

Gambar 2. Pembelajaran dengan Timbangan Bilangan

Inovasi yang dikenalkan pada pembelajaran di bulan April 2018, relawan mengenalkan timbangan bilangan kepada siswa SD, berdasarkan pengamatan pada siswa bernama Rani, Salwa dan Ghofur bahwa mereka menikmati belajar menggunakan media tersebut. Peneliti bertanya pada siswa dan orangtuanya bahwa media tersebut belum pernah mereka dapatkan di kelas. Semua siswa senang karena melihat matematika menjadi nyata dengan dihubungkan operasi penjumlahan, pengurangan, perkalian dan pembagian.Dengan media matematika menjadi mudah dipahami dan belajar matematika menjadi menyenangkan.

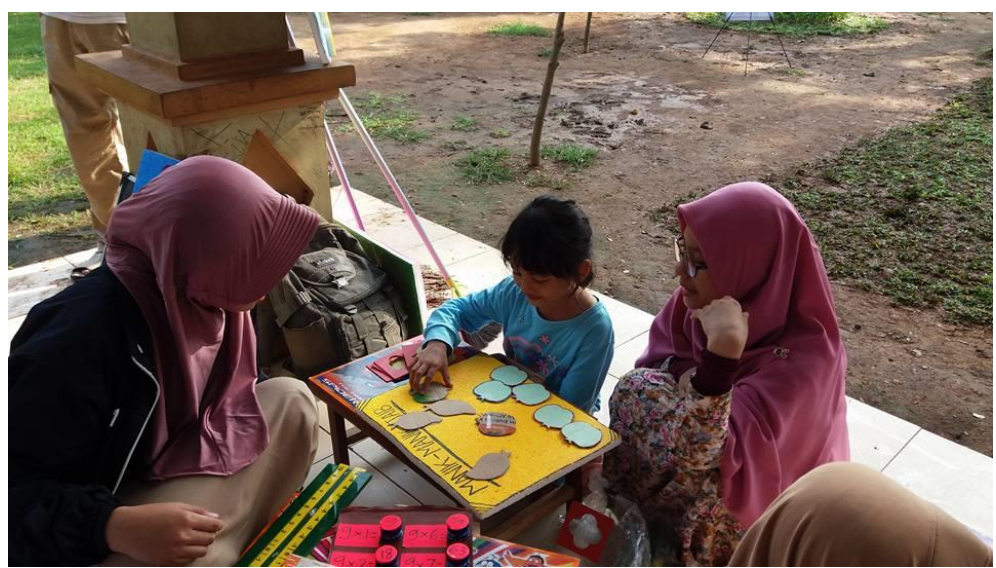

Gambar 3. Pembelajaran dengan Media Kartu Buah-buahan

Inovasi berikutnya dikenalkan ke siswa AUD yang bernama Kanaya berusia 5 tahun, berdasarkan pengamatan Kanaya terlihat sedang asyik memasangkan media kertas bentuk buah-buahan dengan dihubungkan dengan bilangan yang disebutkan. Misal 5 
maka Kanaya memasangkan pola buah apel mendatar, ia pun mampu menyusun bentuk lain dari media kertas buah mangga dengan posisi vertikal. Dari wawancara yang dilakukan kepada Kanaya, ia merasa senang bisa belajar di Puskesmas karena banyak media yang menarik, kemudian orangtua Kanaya pun menyampaikan rasa senangnya karena anaknya bisa kreatif dalam belajar matematika

\section{Inovasi Pembelajaran Matematika Minggu Kedua}

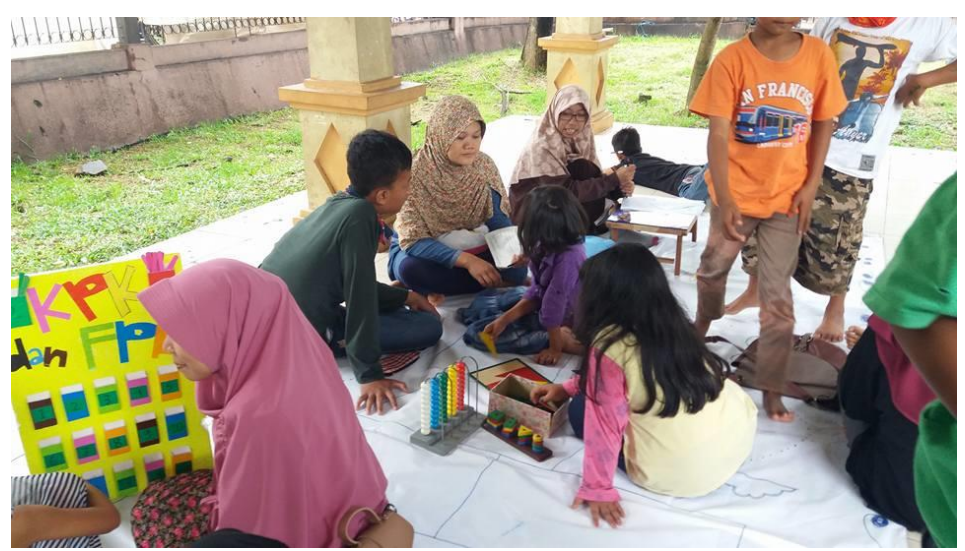

Gambar 4. Media FPB dan KPK

Inovasi yang dikenalkan adalah media FPB dan KPK dengan menggunakan barang bekas yang disusun oleh relawan puskesmas. Siswa yang belajar menggunakan Novi dan Zahra siswa kelas 4, mengalami kesulitan dalam memahami FPB dan KPK di sekolahnya, kemudian setelah dibimbing oleh relawan, dengan menggunakan media tersebut, mereka menjadi paham dan terihat senang dengan tertawa karena belajar matematika menjadi mudah.Berdasarkan wawancara yang dilakukan mereka mengatakan bahwa materi FPB dan KPK biasanya diajarkan hanya dengan ceramah saja, setelah diberikan media, kami bisa memainkan media dengan soal yang diberikan kakak di Puskesmas.

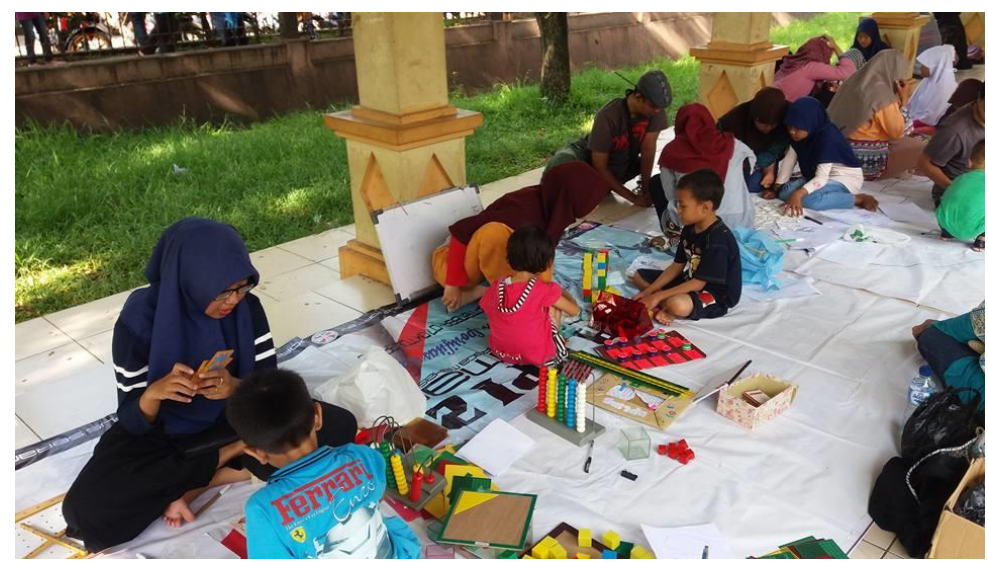

Gambar 5. Media Kubus Berwarna

Inovasi pembelajaran matematika yang dikenalkan pada Hanaya merupakan AUD berusia 5 tahun adalah kubus-kubus berwarna, berdasarkan pengamatan ia memasangkan kotak-kota kubus warna dengan dihubungkan konsep geometri. Hanaya 
telah membuat ide dalam belajar matematik dengan lancar membuat gagasan baru dengan memasangkan kotak dengan cara mendatar dan tegak. Hanaya pun mengemukakan gagasan dengan menyusun kotak-kotak kubus warna dengan bervariasi. Dari wawancara yang dilakukan pada Hanaya, ia merasa suka belajar matematika dengan memasangkan kubus begitu pun orang tua yang mendampinginya merasa senang anaknya bisa belajar di Puskesmas.

\section{Inovasi Pembelajaran Matematika Minggu Ketiga}

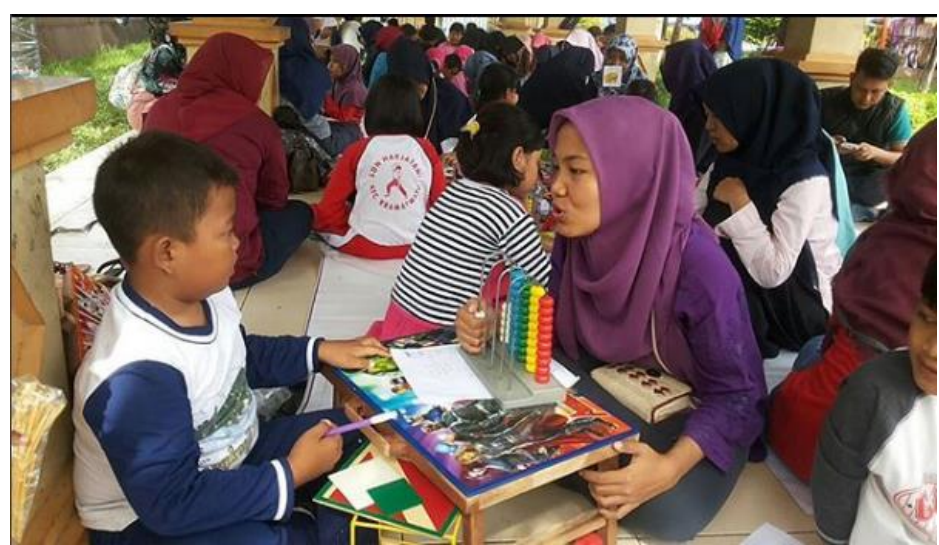

Gambar 6. Media Dekak-dekak

Inovasi yang disajikan pada siswa SD bernama Sandi kelas 2 SD, adalah dekak-dekak yang bisa digunakan untuk memudahkan dalam operasi penjumlahan dan pengurangan untuk kelas rendah. Sandi merasa senang dan fokus konsentrasi memperhatikan bimbingan dari relawan puskesmas. Orangtua mendampingi dan memberikan kesan positif agar program ini terus berjalan.Proses belajar walau berdesakan namun anaknya tetap berkonsentrasi mendengarkan bimbingan dari kakak di Puskesmas.

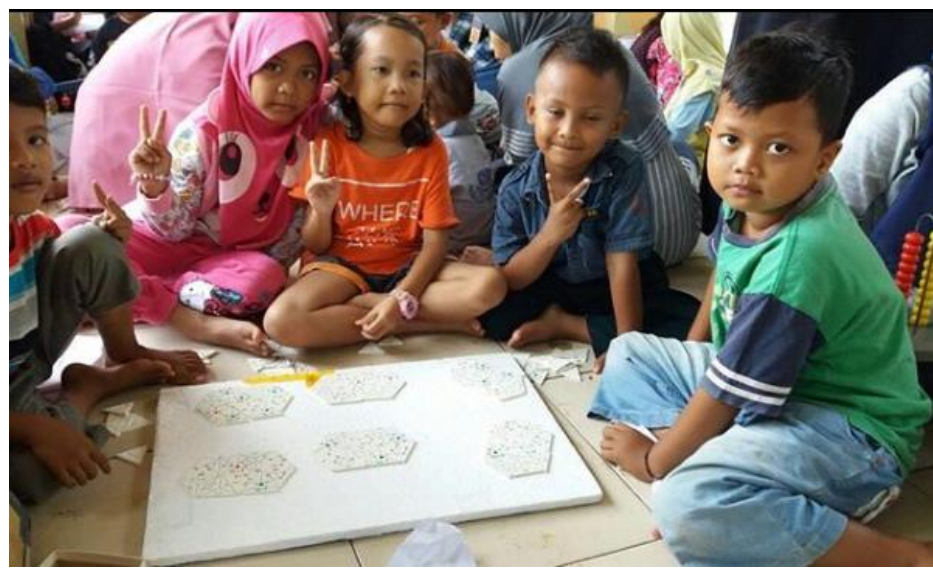

Gambar 7. Media Keping segitiga-segitiga

Inovasi yang disajikan adalah keping-keping segitiga matematika kepada Rahmat merupakan AUD berusia 5 tahun, Mput berusia 5. Berdasarkan pengamatan mereka memasangkan segitiga-segitiga angka menjadi sebuah pola geometri, jika peneliti amati bentuk ini menyerupai heksagon. Rahmat dan Mput telah membuat gagasan baru 
dengan memasangkan segitiga-segitga dengan rapi dan terpola. Rahmat dan Mput pun memiliki mengemukakan gagasan dengan menyusun berbagai bentuk segitiga dengan pola-pola yang teratur. Dari wawancara yang dilakukan pada Rahmat dan Mput, mereka senang belajar matematika dengan memasangkan media segitga-segitiga begitu pun orang tua yang mendampinginya merasa senang anaknya bisa belajar di Puskesmas.

\section{Inovasi Pembelajaran Matematika Minggu Keempat}

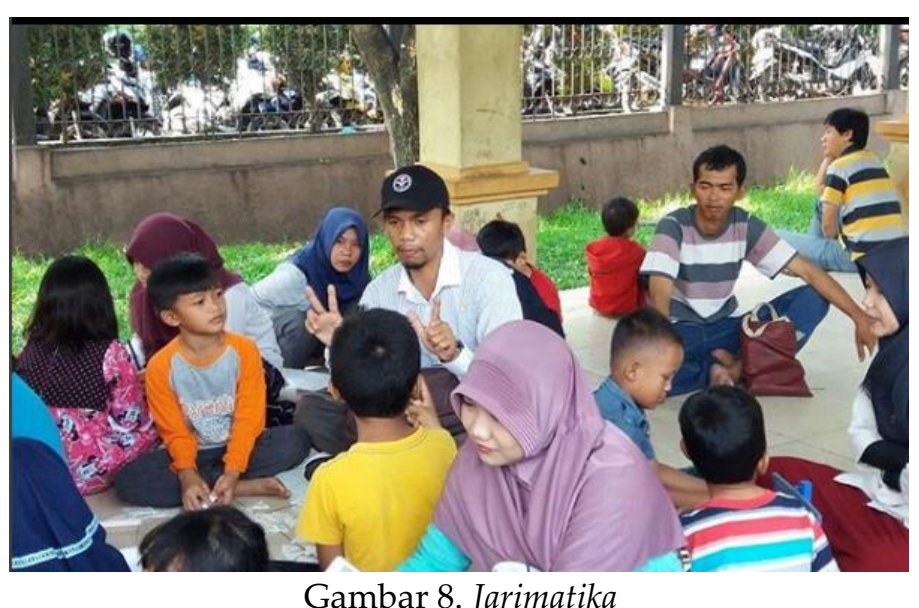

Inovasi yang disajikan pada siswa SD bernama Azka 4 SD, adalah jarimatika yang bisa digunakan untuk memudahkan dalam operasi perkalian dari 6-15. Azka menyenangi dan fokus konsentrasi memperhatikan bimbingan dari Ayahnya, pendiri puskesmas. Jarimatika menjadi memudahkan Azka dalam mengalikan dua bilangan, tanpa harus membuat di kertas. Orangtua Azka berpendapat dengan Jarimatika anak bisa belajar berpikir dalam menyimpan bilangan dalam otaknya yang dikaitkan dengan jari-jari.

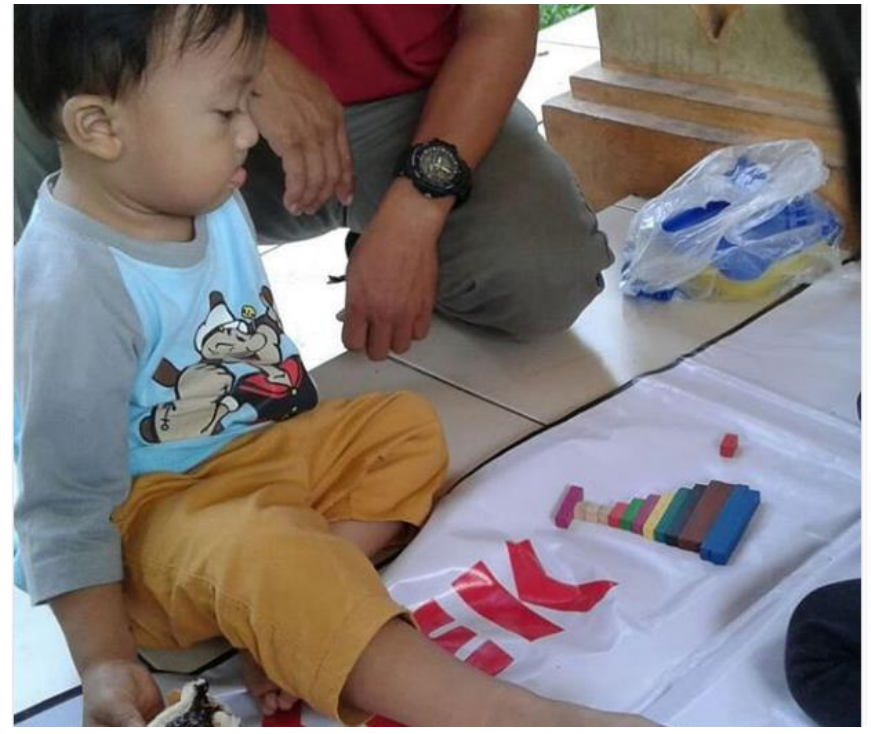

Gambar 9. Media Batang Kuisener 
Inovasi yang disajikan kepada Adam AUD berusia 3 tahun, Adam memasangkan batang kuisinare menjadi sebuah pola geometri dan bilangan, jika peneliti amati bentuk ini disusun dari terkecil sampai terbesar. Adam telah membuat gagasan baru dengan memasangkan batang kusinare dengan rapi dan terpola. Adam pun mengemukakan gagasan dengan menyusun berbagai posisi batang dengan pola-pola yang teratur. Dari wawancara yang dilakukan pada orang tua Adam, Adam merasa senang belajar matematik dengan memasangkan batang kuisanare yang berwarna.

\section{Pembahasan}

Berdasarkan data pengamatan, dokumentasi dan wawancara terhadap siswa dan orangtua bahwa media yang disajikan di Puskesmas semua baru dan belum mereka dapatkan di sekolah masing-masing. Temuan ini dikuatkan oleh penelitian Andrijati (2014) bahwa fenomena di sekolah menunjukkan bahwa dalam pembelajaran matematika masih terdapat kecendrungan guru jarang menggunakan media/alat peraga seadanya atau sangat sederhana, jauh dari menarik perhatian siswa.Selain itu Kusmiyatin dkk (2018) mengatakan bahwa saat ini masih diperlukan pengembangan media yang merupakan salahsatu alat bantu proses mengajar dengan harapan siswa lebih mudah memahami dan senang belajar matematika.

Berdasarkan Pengamatan terhadap siswa terlihat bahwa inovasi pembelajaran matematika yang disajikan di Puskesmas berdampak pada sikap siswa yang menjadi senang, suka, ceria dalam belajar matematika dan mudah memahami konsep matematika.Selain itu proses bimbingan belajar puskesmas memunculkan kreativitas siswa AUD dan SD dalam belajar matematika. Temuan ini dikuatkan oleh penelitian penulis sebelumnya bahwa kreativitas AUD di Pusat Kesehatan Matematika Sekolah menurut Supriadi (2017) dapat dikembangkan dengan inovasi media dan permainan yang disajikan dalam bimbingan belajar matematika untuk AUD berbasis alun-alun. Selain itu pendapat Nasution (2017) bahwa penggunaan media dalam pembelajaran matematika di TK sangat diperlukan, karena sesuai dengan tahap berpikir anak, Dengan menggunakan media siswa akan lebih menghayati matematika secara nyata berdasarkan fakta yang jelas, sehingga siswa lebih mudah memahami konsep yang disajikan oleh guru.

Konsentrasi siswa pun meningkat karena model pembelajaran yang digunakan menggunakan pendekatan individu, sehingga bisa lebih fokus melihat proses belajar siswa. Temuan ini didukung dengan temuan Mulyana dkk (2013) bahwa siswa yang meningkat konsentrasinya dapat mudah memahami pelajaran dan mampu meningkatkan prestasinya.

Orangtua yang mendampingi anaknya pada umumnya merasa senang karena anaknya menjadi senang belajar matematika. Karena Belajar puskesmas gratis, memudahkan kami orangtua yang kurang memiliki biaya untuk mendaftarkan ke bimbingan belajar yang relatif mahal. Semua orangtua berharap program ini terus berlanjut. Cara belajar di Alun-alun memudahkan orangtua menuju Puskesmas, karena mudah mencari alat transportasi menuju ke Puskesmas. 


\section{SIMPULAN}

Berdasarkan hasil pembahasan disimpulkan bahwa kegiatan pengabdian pusat kesehatan matematika sekolah (Puskesmas) dalam pembelajaran matematika berbasis Alun-alun kota berdampak pada siswa AUD dan SD menjadi senang belajar matematika, suka belajar dengan media matematika,ceria dalam mengikuti bimbingan belajar matematika dan menikmati belajar matematika. Program ini pun sangat didukung oleh orangtua karena sangat membantu pada proses pembelajaran anaknya dan meringankan beban ekonomi keluarga dalam pendidikan.

\section{REFERENSI}

Andrijati, N. (2014). Penerapan media pembelajaran inovatif dalam pembelajaran matematika sekolah dasar di PGSD UPP Tegal. Jurnal Penelitian Pendidikan, 31(2), 123132.

Hasan, H. (2015). Kendala yang dihadapi guru dalam proses belajar mengajar matematika di SD Negeri Gani Kabupaten Aceh Besar. Jurnal Pesona Dasar, 1(4), 4051.

Kusmiyati, K., Ardianik, A., \& Kadar, S. (2018). Iptek bagi masyarakat usaha meningkatkan pembelajaran matematika yang inovatif dan menyenangkan berbantuan media bagi guru-guru sekolah dasar. JPM17: Jurnal Pengabdian Masyarakat, 3(1), 64-67.

Mulyana, O. P., Izzati, U. A., \& Puspitadewi, N. W. S. (2013). Penerapan relaksasi atensi untuk meningkatkan konsentrasi belajar pada siswa SMK. Jurnal Psikologi Teori dan Terapan, 3(2), 103-112.

Nasution, F. S. (2017). Penerapan media pembelajaran inovatif dalam pembelajaran matematika logis untuk anak usia dini. In Prosiding Seminar Nasional Tahunan Fakultas Ilmu Sosial Universitas Negeri Medan (pp. 227-230). Medan: Universitas Negeri Medan.

Soekirno. (2011). Bimbingan belajar perlukah?. Retrieved October 7, 2017 from https://nasional.kompas.com/read/2011/10/07/12390757/bimbingan.belajar.perlukah ?page $=$ all

Supriadi. (2008). Penggunaan kartun matematika dalam pembelajaran matematika. Jurnal Pendididkan Dasar, 2(10), 1-6.

Supriadi. (2016). Kreativitas guru dan siswa melalui pembelajaran etnomatematika Sunda. In Seminar Nasional Pendidikan Dasar UPI Kampus Serang. Serang, 14 Mei 2016.

Supriadi. (2017). Bakti pendidikan pusat kesehatan matematika sekolah (Puskesmas) bagi anakanak usia dini di alun-alun Kota Serang melalui pembelajaran matematika menyenangkan. Laporan PPM Prodi PGPAUD UPI. Serang: UPI Kampus Serang.

Susanti dan Maharani (2015). Ibm membangun“Desa Cermat”Melalui Bimbingan Belajar dalam Meningkatkan Hasil Belajar Matematika Siswa. Jurnal Terapan Abdimas,1,39-42 
Widjajanti (2009). Difusi inovasi pendidikan matematika realistik melalui lesson study. In KNPM3 Universitas Negeri Yogyakarta. Yogyakarta, 2009.

\section{Copyright and License}

This is an open access article distributed under the terms of the Creative Commons Attribution 4.0 International License, which permits unrestricted use, distribution, and reproduction in any medium, provided the original work is properly cited. (C) 2020 Supriadi.

Published by LP3M of Universitas Mathla'ul Anwar Banten in collaboration with the Asosiasi Jurnal Pengabdian Kepada Masyarakat (AJPKM) 